HOW TO FEEL 



\section{HOW TO FEEL}

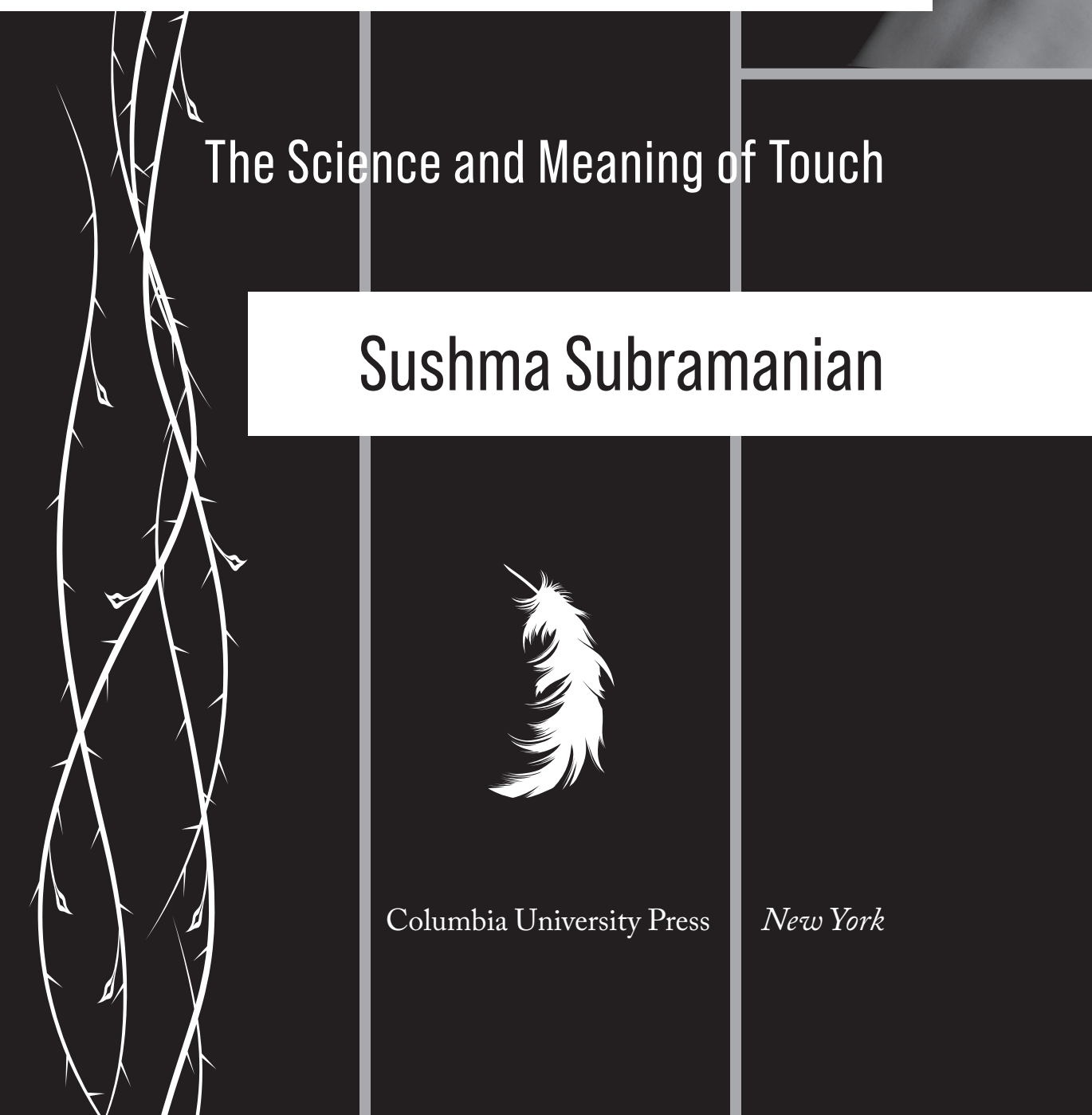




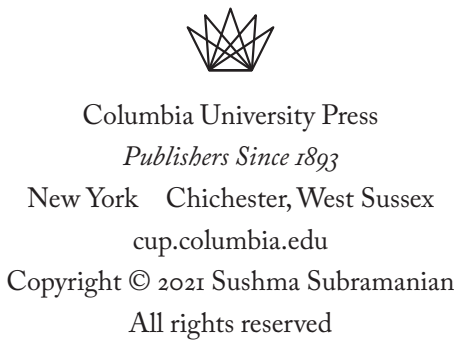

Library of Congress Cataloging-in-Publication Data

Names: Subramanian, Sushma, author.

Title: How to feel : the science and meaning of touch /

Sushma Subramanian.

Description: New York : Columbia University Press, [202I] |

Includes bibliographical references and index.

Identifiers: LCCN 2020019034 (print) | LCCN 2020019035 (ebook) |

ISBN 978023 II99322 (hardback) | ISBN 9780231553056 (ebook)

Subjects: LCSH: Touch.

Classification: LCC QP 45I .S82 202I (print) | LCC QP 45I (ebook) |

DDC 6I2.8/8-dc23

LC record available at https://1ccn.loc.gov/2020019034

LC ebook record available at https://lccn.loc.gov/20200I9035

Columbia University Press books are printed on permanent and durable acid-free paper.

Printed in the United States of America

Cover images: Cactus, coffee cup, torso: Adobe Stock Images; hand in the dark: Loic Lambour / Millennium Images, UK; tulip:

Magdalena Wasiczek / Trevillion Images; haptic glove:

John D. Ivanko / Alamy Stock Photo

Cover design: Lisa Hamm 
Why was the sight

To such a tender ball as the eye confined

So obvious and so easy to be quench'd?

And not, as feeling, through all parts diffused,

That she might look at will through every pore.

-John Milton, from Samson Agonistes 
